\title{
Behaviour of a Cylindrical Reinforced Carbon Fibre Shell Under Impact Load
}

\author{
Aleksandr L. Medvedskiy, Mikhail I. Martirosov, \\ Anton V. Khomchenko, Darina V. Dedova \\ Moscow Aviation Institute (National Research University), Volokolamskoe Highway, 4 \\ 125993, Moscow, Russia
}

\begin{abstract}
This work is devoted to numerical analysis of the behaviour of reinforced cylindrical shell made of a polymer composite material (PCM) under the action of an unsteady shock load, taking into account interlayer defects of elliptical shape, as well as evaluate the strength of composite package and the development of delaminations.
\end{abstract}

Keywords - cylindrical reinforced shell, composite, composite failure criteria, interlayer defect, unsteady load, numerical modelling, finite element method (FEM).

\section{Introduction}

Increased requirements for new types of equipment in various fields of mechanical engineering lead to the need to use modern structural materials, which in their characteristics should be superior to traditional metal materials. The use of PCM in creating structural elements has become widespread.

DOI: $10.18421 /$ TEM104-14

https://doi.org/10.18421/TEM104-14

Corresponding author: Aleksandr L. Medvedskiy, Moscow Aviation Institute (National Research University), Moscow, Russia.

Email: medvedskiy mai@mail.ru

Received: 09 June 2021.

Revised: 23 September 2021.

Accepted: 29 September 2021.

Published: 26 November 2021.

(cc) BY-NC-ND (C) 2021 Aleksandr L. Medvedskiy et al; published by UIKTEN. This work is licensed under the Creative Commons Attribution-NonCommercial-NoDerivs 4.0 License.

The article is published with Open Access at www.temjournal.com
With all the advantages, PCM products are sensitive to internal defects that may appear at various stages of production and operation. The paper describes the general principles of modelling layered structures with internal defects between layers using software systems (LS-DYNA, Siemens Femap) on the basis of FEM. The results of calculations for a cylindrical circular reinforced shell made of high-modulus carbon fibre and under the action of a shock load are presented. The behaviour of the shell with and without elliptical defects is analysed. It defines the fields of the stresses, deformations and displacements in the monolayers at different points in time.

\section{Materials and Methods}

To study the behaviour of a reinforced shell in the presence of interlayer defects, we propose to use the following algorithm [1]:

- modelling each monolayer of a composite package with a separate set of finite elements;

- connection of layers of elements by means of glue contact, except for zones where defects are located, in these zones one-sided contact is considered;

- $\quad$ setting the appropriate material properties, laying direction, application of load and boundary conditions to the model;

- performing the calculation and obtaining the necessary results (in the LS-DYNA software package).

\section{Statement of the Problem}

The object of this study is a reinforced cylindrical shell made of PCM with a length of $L=800 \mathrm{~mm}$ and a radius of $R=200 \mathrm{~mm}$ (Figure 1.). 


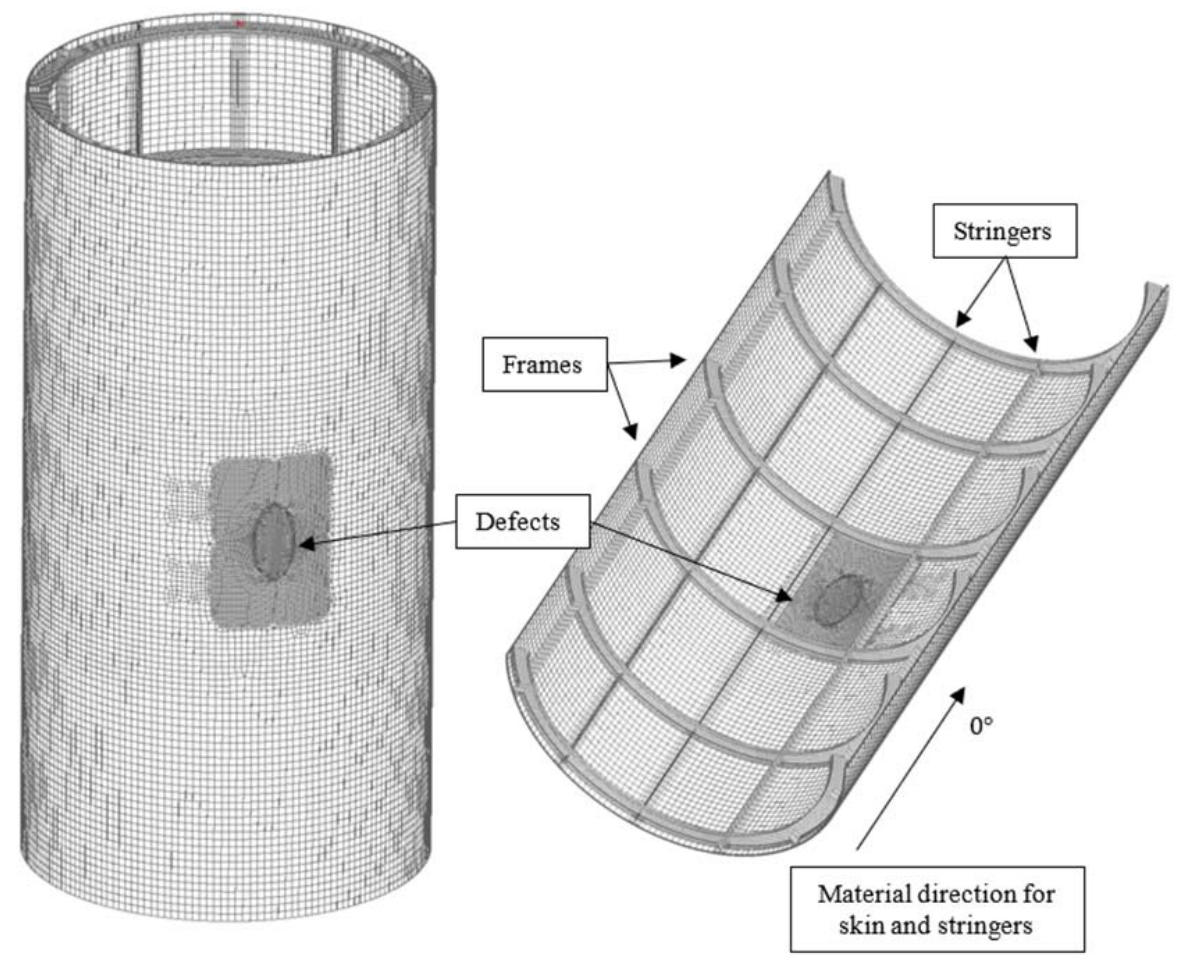

Figure 1. Reinforced cylindrical shell

The shell (skin, stringers and frames) is made of carbon fibre using autoclave technology based on prepreg HexPly M21/34\%/UD194/IMA (IMA carbon tape based high-strength fiber HexTow IMA-12K and modified epoxy binder M21) manufactured by Hexcel Composites (USA). The thickness of the monolayer is assumed to be $h=0.184 \mathrm{~mm}$. Laying shell has the following scheme: $[+45 \%$ $\left.45^{\circ} / 90^{\circ} / 0^{\circ} /+45^{\circ} /-45^{\circ} /-45^{\circ} /+45^{\circ} / 0^{\circ} / 90^{\circ} /-45^{\circ} /+45^{\circ}\right]$

(total 12 monolayers, total package thickness 2.208 $\mathrm{mm})$. The stringer has a T-shaped cross section $(11 \times 14 \mathrm{~mm})$, the cross-section of the frames is a channel $(20 \times 6 \mathrm{~mm})$. It is assumed that between layers $1-2,2-3$, etc. to $11-12$ (one under the other) there are elliptical defects with axes of 80 and $45 \mathrm{~mm}$. As boundary conditions, a hinge support is used at the ends of the shell [2], [3].

The problem is solved using FEM in the LSDYNA software package. Each monolayer is modeled by a separate set of finite elements with the formulation «16: Fully integrated shell element» and the «COMPOSITE» property [4], [5]. Layers, except for defect zones, are connected to each other by the glue contact «AUTOMATIC_ONE_WAY_SURFACE_TO_SUR FACE_TIEBREAK». The contact «AUTOMATIC_SURFACE_TO_SURFACE» is taken into account between defects.

\section{Failure Criteria}

To assess the strength of carbon fibre, the ChangChang (1)-(5) failure criteria is used, which allows evaluating the strength of the matrix and fibre separately (this criterion is implemented in the material model:

\section{«054/055_ENHANCED_COMPOSITE_DAMAGE» ) [6], [7].}

The strength of the fibre for a flat stressed state is determined by the following relations (1) - (5):

Fibre strength:

$$
\begin{gathered}
f_{f}=\left(\frac{\sigma_{1}}{\mathrm{x}_{\mathrm{T}}}\right)^{2}+\beta_{1}\left(\frac{\tau_{12}}{\mathrm{~s}_{12}}\right)=1 \text { at } \sigma_{1} \geq 0, \\
f_{f}=\left(\frac{\sigma_{1}}{\mathrm{x}_{\mathrm{C}}}\right)^{2}=1 \text { at } \sigma_{1}<0
\end{gathered}
$$

Matrix strength:

$$
\begin{gathered}
f_{m}=\left(\frac{\sigma_{2}}{\mathrm{Y}_{\mathrm{T}}}\right)^{2}+\left(\frac{\tau_{12}}{\mathrm{~S}_{12}}\right)^{2}=1 \text { at } \sigma_{2} \geq 0 . \\
f_{f}=\left(\frac{\sigma_{1}}{\mathrm{x}_{\mathrm{C}}}\right)^{2}=1 \text { at } \sigma_{1}<0 . \\
f_{f}=\left(\frac{\sigma_{1}}{\mathrm{x}_{\mathrm{C}}}\right)^{2}=1 \text { at } \sigma_{1}<0 .
\end{gathered}
$$

where $f_{f}$ is the fibre failure index, $f_{m}$ is the matrix failure index, $\sigma_{1}$ is the normal stress acting in the longitudinal direction, $\sigma_{2}$ is the normal stress acting in the transverse direction, $\tau_{12}$ is the shear stress acting in the plane of the sheet, $X_{T}$ is the tensile strength in longitudinal direction in tensile, $X_{C}$ is the tensile strength in longitudinal direction in compressive, $Y_{T}$ is the tensile strength in transverse direction in tensile, $Y_{C}$ is the tensile strength in the transverse direction in compression, $S_{12}$ is the ultimate strength in shear. The coefficient $\beta_{1}$ is assumed to be 0.1 . 
The option corresponding to the material model «MAT_COHESIVE_MIXED_MODE» is used as a mathematical model of the interlayer adhesive joint material. This model implements a bilinear description of the material behaviour using a mixed quadratic delamination criterion [8], [9]. The relative movement of elements is set as follows (6):

$$
\delta_{m}=\sqrt{\delta_{I}^{2}+\delta_{I I}^{2}},
$$

where $\delta_{I}=\delta_{3}$ is the displacement in the normal direction, $\delta_{I I}=\sqrt{\delta_{1}^{2}+\delta_{2}^{2}}$ is the displacement in the tangent direction.

The criterion for the beginning of degradation of the adhesive contact by displacement has the following form (7):

$$
\delta^{0}=\delta_{I}^{0} \delta_{I I}^{0} \sqrt{\frac{1+\beta^{2}}{\left(\delta_{I I}^{0}\right)^{2}+\left(\beta \delta_{I}^{0}\right)^{2}}}
$$

where $\quad \beta=\frac{\delta_{I I}}{\delta_{I}}, \delta_{I}^{0}=\frac{T}{E N}, \delta_{I I}^{0}=\frac{S}{E T}, \quad T \quad$ is $\quad$ the maximum stresses in the normal direction, $S$ is the maximum stresses in the tangent direction, $E N$ is the material stiffness in the normal direction, ET is the material stiffness in the tangent direction.

The criterion of complete destruction has the following form (8):

$$
\delta^{F}=\frac{2\left(1+\beta^{2}\right)}{\delta^{0}}\left[\left(\frac{E N}{G_{1 C}}\right)^{X M U}+\left(\frac{E T \cdot \beta^{2}}{G_{2 C}}\right)^{X M U}\right]^{-\frac{1}{X M U}},
$$

where $G_{1 C}$ is the energy of destruction under the normal separation, $G_{2 C}$ is the energy of destruction at a plane shift, $X M U$ is the degree of the equation.
The following values are used to set the properties of the adhesive contact: $T=15 \mathrm{MPa}, S=15 \mathrm{MPa}$, $E N=E T=10^{5} \mathrm{MPa}, G_{1 C}=G_{2 C}=0.2 \mathrm{~J} / \mathrm{mm}^{2}$.

The carbon fibre monolayer material has the following mechanical characteristics $X_{T}=$ $2830 \mathrm{MPa}, X_{C}=1500 \mathrm{MPa}, Y_{T}=54 \mathrm{MPa}$, $Y_{C}=271 \mathrm{MPa}, S_{12}=96 \mathrm{MPa}, E_{1}=149 \mathrm{GPa}$, $E_{2}=7.4 \mathrm{GPa}, G=3.9 \mathrm{GPa}, \mu_{12}=0.32, \rho=$ $1580 \mathrm{~kg} / \mathrm{m}^{3}$. Here $\mu_{12}$ - the Poisson's ratio that characterizes transverse compression in the longitudinal direction, $G$ - the shear modulus, $\rho$ - the density, $E_{1}$ - the elastic modulus in the longitudinal direction, $E_{2}$ - the elastic modulus in the transverse direction. The characteristics of the monolayer were obtained by the PCM manufacturer experimentally on samples according to European EN standards for RTD (Room Temperature Dry) mode: normal temperature $+23^{\circ} \mathrm{C}$ and humidity - in the delivery state [10], [11].

\section{External Influence}

The impact of a rigid impactor is considered as an external impact [12], [13]. Figure 2. shows a finite element model of an impactor, which is a rigid hemispherical tip with a distributed mass. The mass $m$ of the striker is assumed to be $5 \mathrm{~kg}$ and distributed using the interpolation finite element «CNRB» [14]. The impact is directed perpendicular to the skin in the centre of the defect [15]. The impact velocity $V$ is considered in two versions: $5 \mathrm{~m} / \mathrm{s}$ and $8 \mathrm{~m} / \mathrm{s}$, so the kinetic energy of the impact $E$ is equal to $62.5 \mathrm{~J}$ and $160 \mathrm{~J}$, respectively.

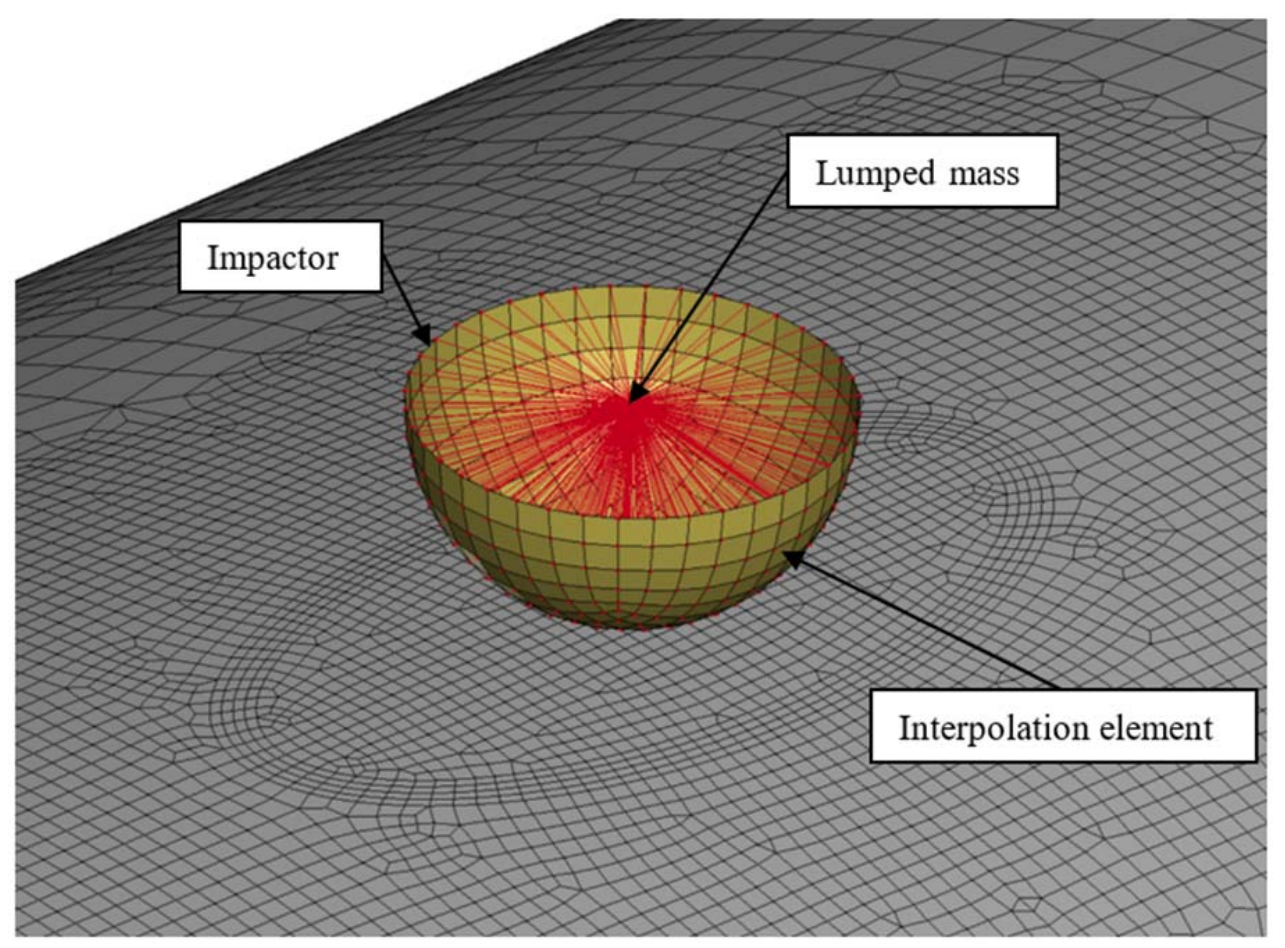

Figure 2. Impactor 


\section{Results and Discussions}

Figure 3. shows the state of the model at various points in time under the action of a shock at $E=160$ $J$.

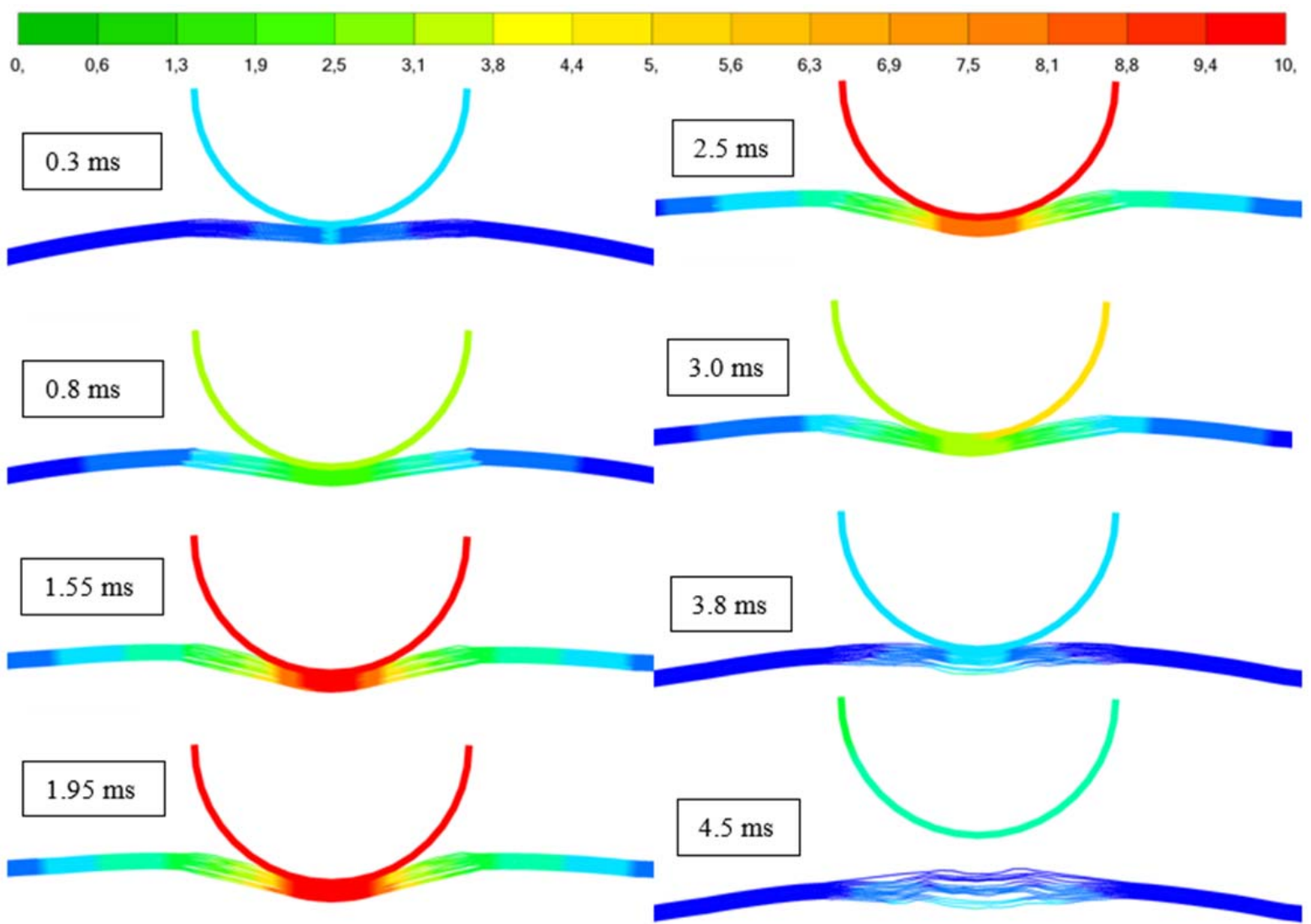

Figure 3. Resultant displacement, $\mathrm{mm}$

Figure 4. shows the change in contact pressure at the collision point of the shell and impactor for the corresponding collision energy levels.

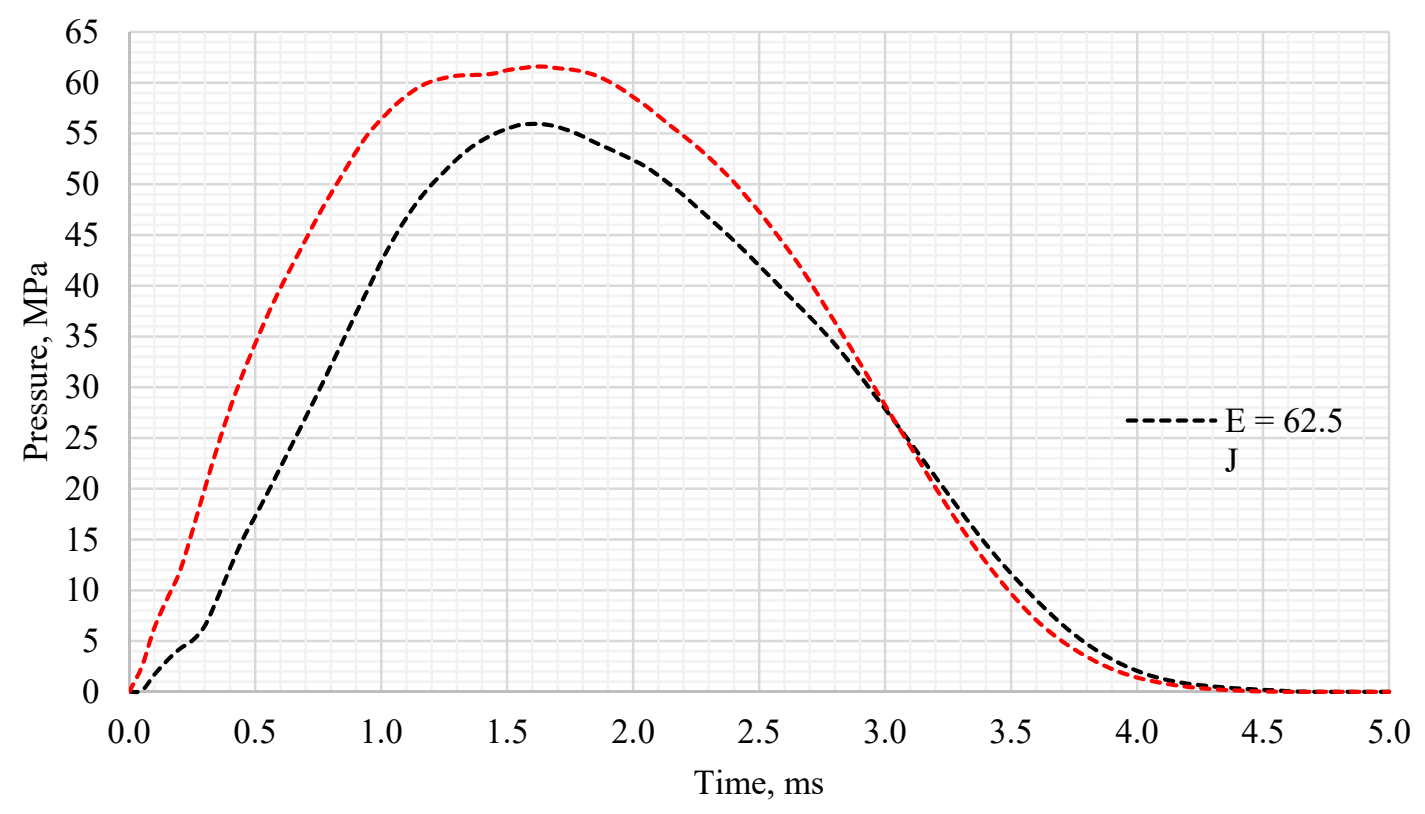

Figure 4. Contact pressure change 
Figure 4. shows that the maximum contact pressure reaches values of 61.6 $\mathrm{MPa}$ and $55.9 \mathrm{MPa}$ at the moment of $1.6 \mathrm{~ms}$ at the impact energy of 160 $J$ and
$62.5 \mathrm{~J}$, respectively. Figure 5. shows the change in the deflection of the skin at the point of impact for the shell with defects and without defects.

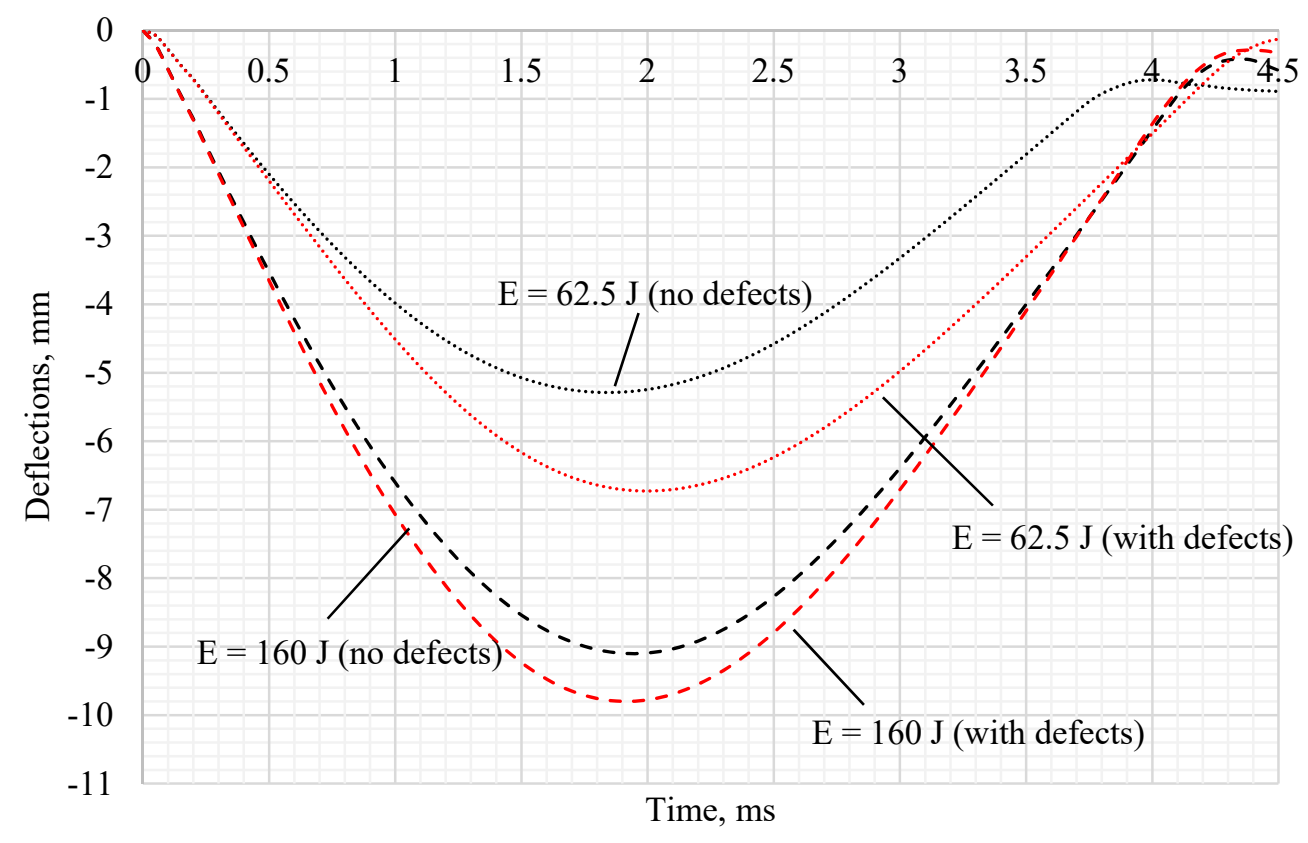

Figure 5. Deflection change

Figure 5. shows that with an impact energy of 62.5 $J$, the maximum deflection in the case of defects is $21.5 \%$ greater than in the case of no defects. At an energy of $160 \mathrm{~J}$, the difference is about $7 \%$. Figure 6 . and Figure 7. show the change in the area of the delamination at different points in time for the shell with defects and without defects.

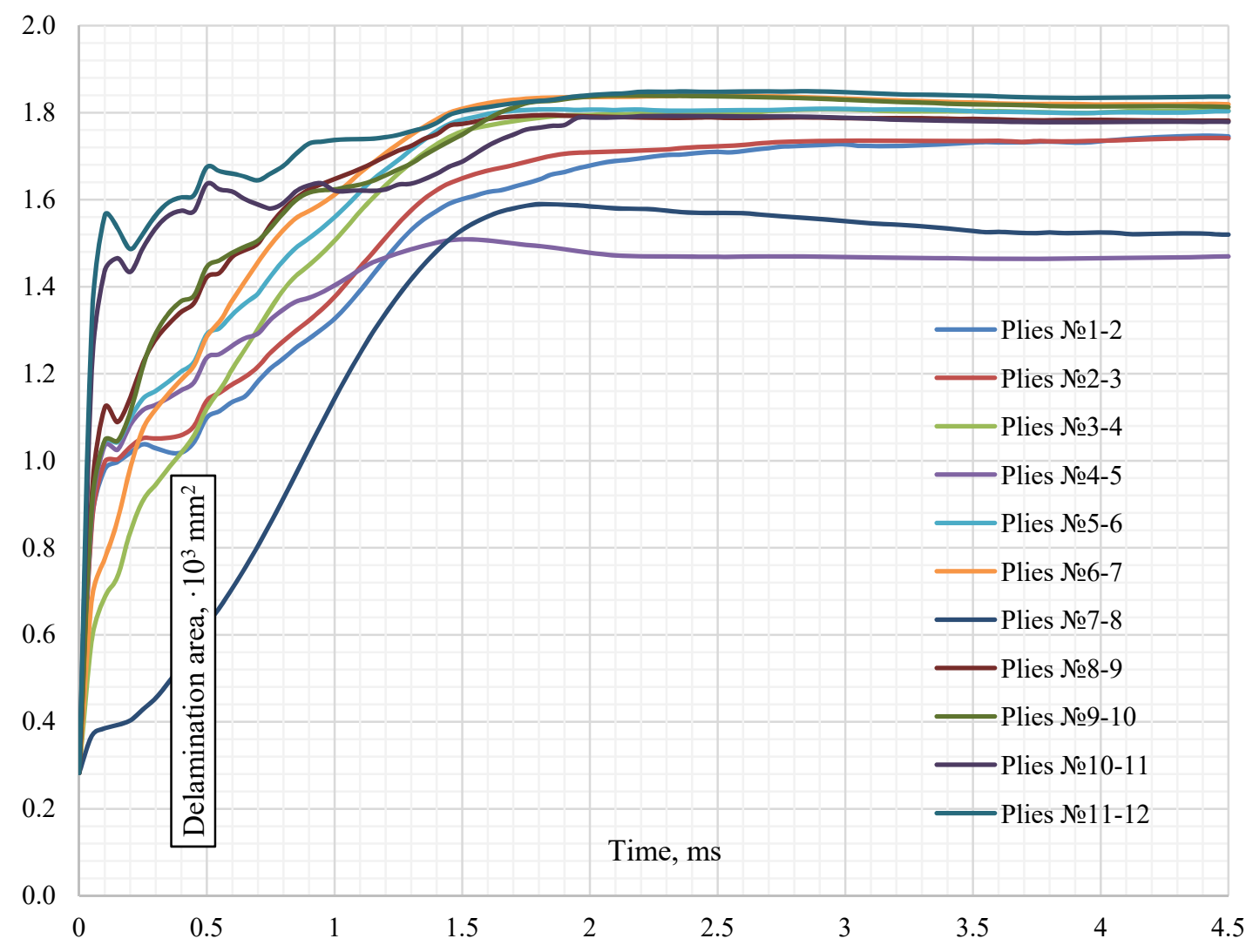

Figure 6. Delamination area between plies (with defects; $E=160 \mathrm{~J}$ ) 
TEM Journal. Volume 10, Issue 4, Pages 1597-1604, ISSN 2217-8309, DOI: 10.18421/TEM104-14, November 2021.

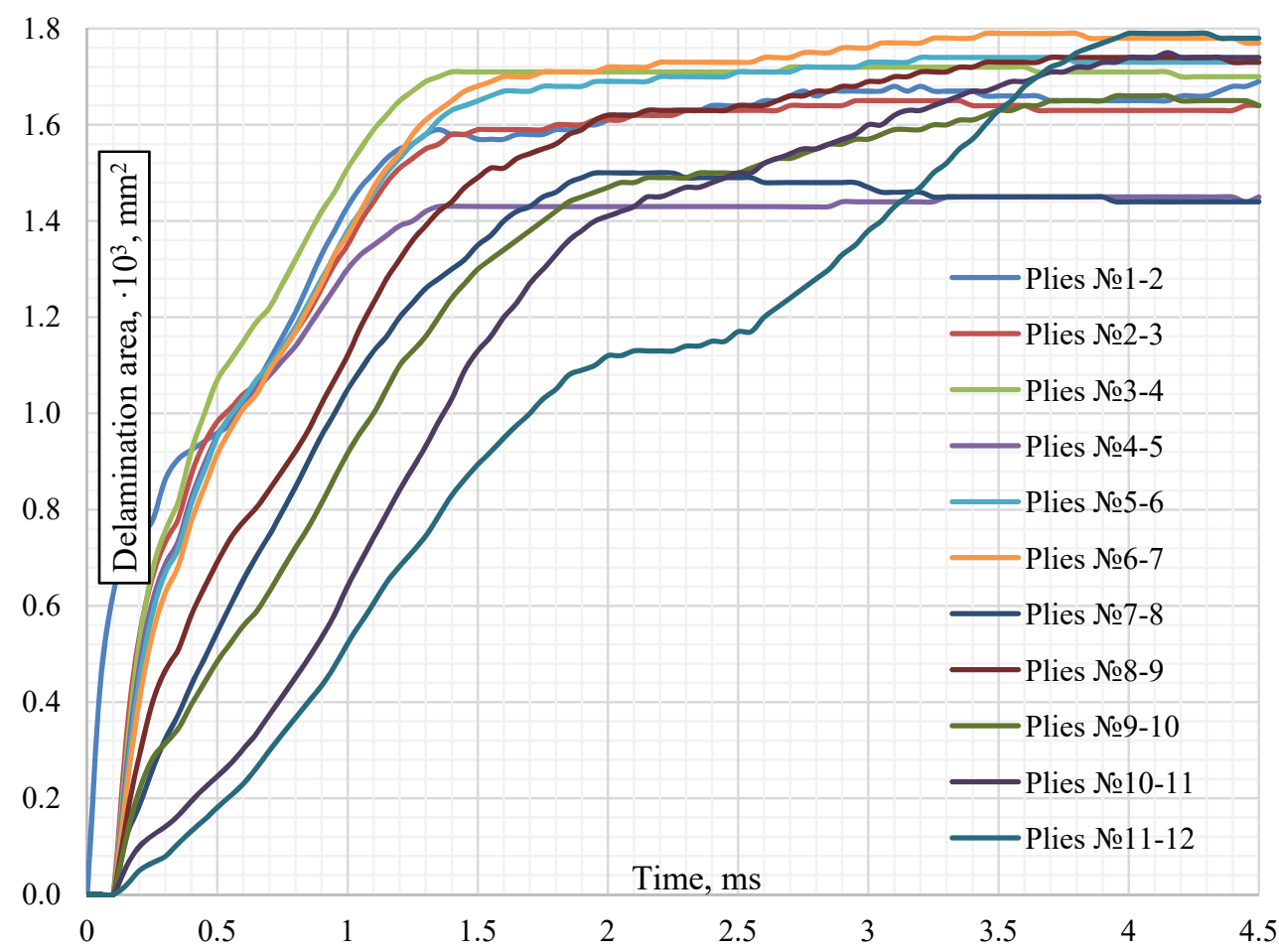

Figure 7. Delamination area between plies (no defects; $E=160 \mathrm{~J}$ )

Figure 8. shows the state of the adhesive interface the presence and absence of defects (stress energy between layers № 4-5 at different points in time for $160 \mathrm{~J}$ ).
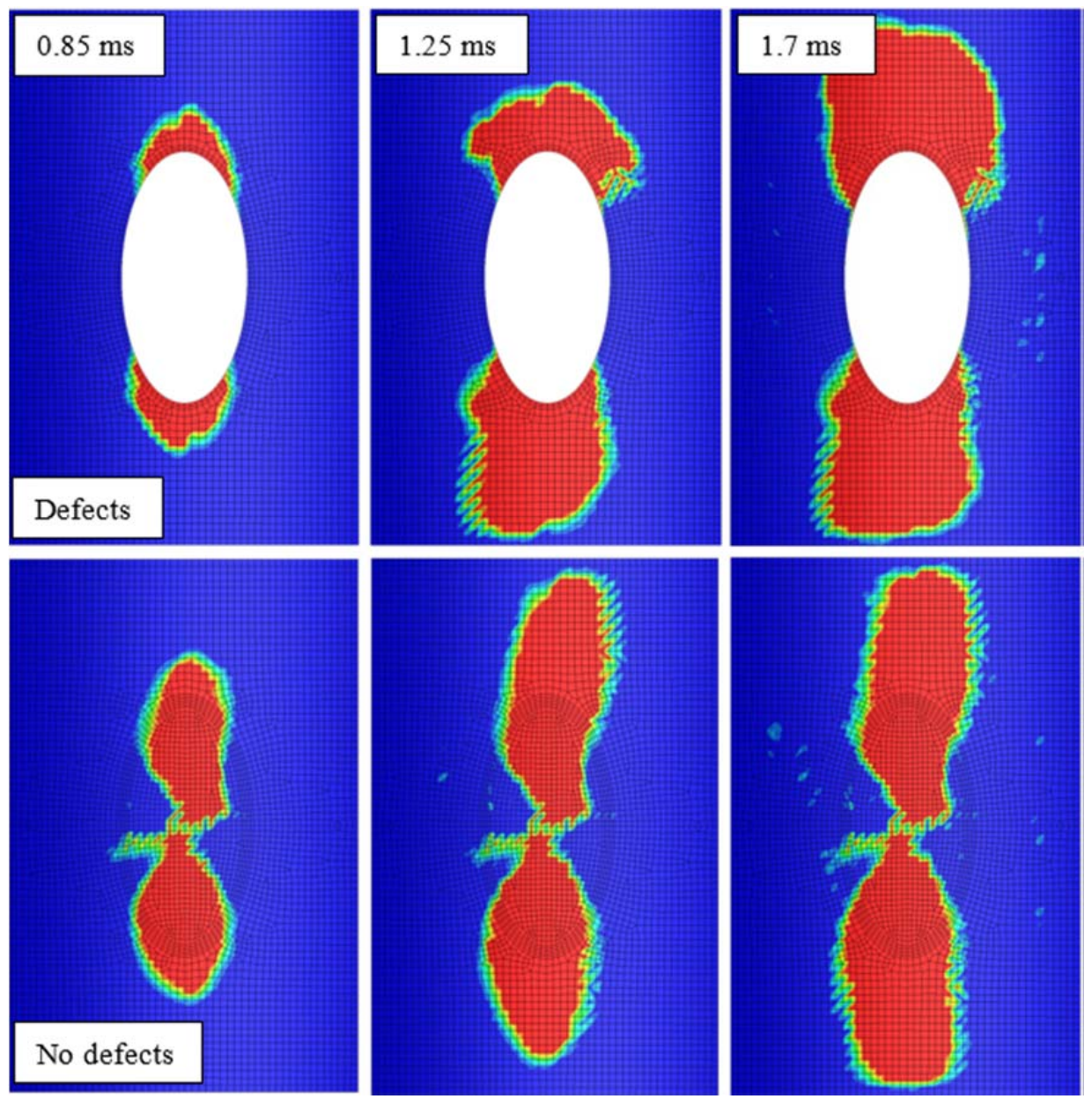

Figure 8. Propagation of delamination $(E=160 \mathrm{~J})$ 
Figure 9. shows the area of matrix failure of the contact layer of the skin at a time of $4.5 \mathrm{~ms}$.
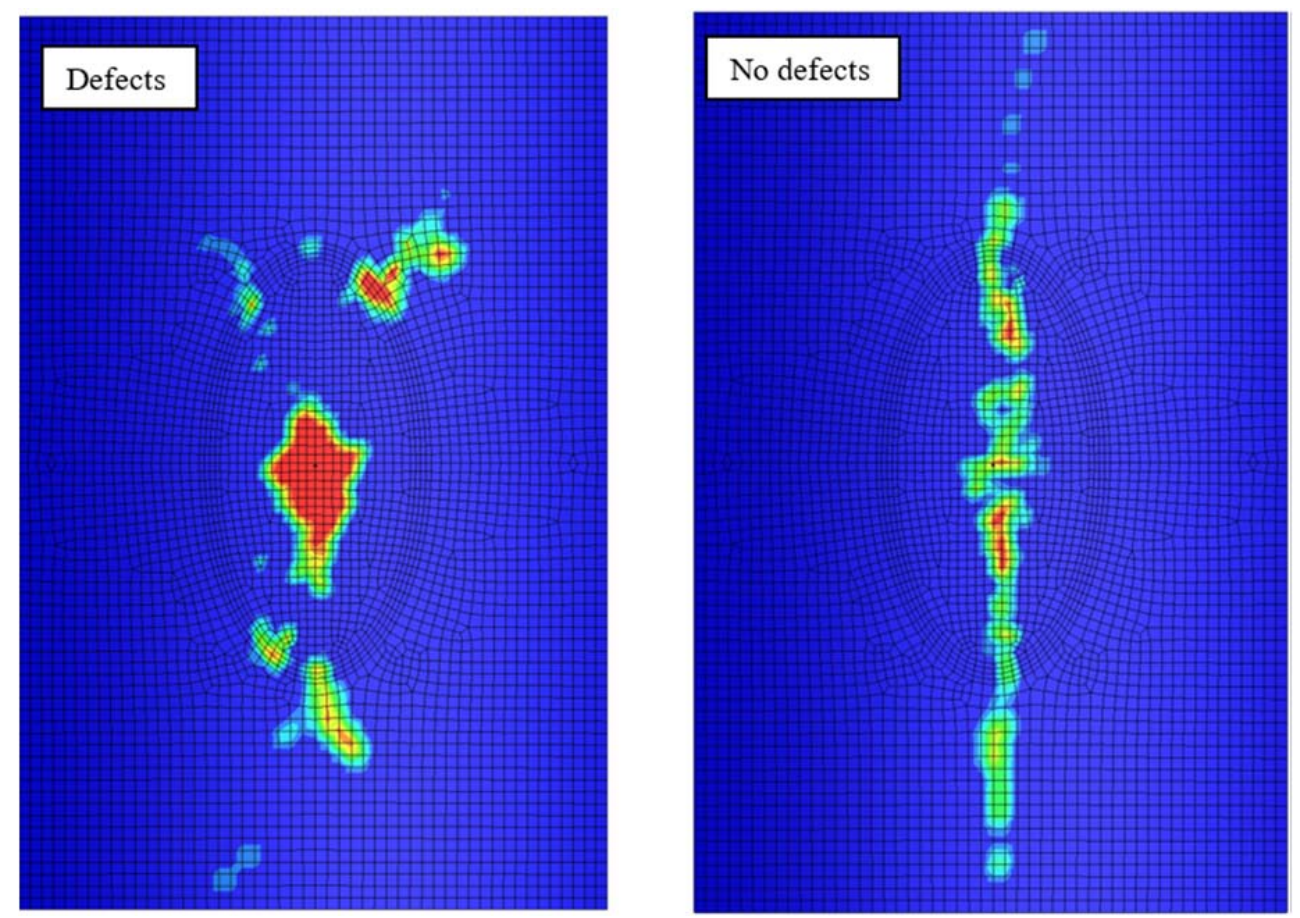

Figure 9. Matrix failure $(E=160 \mathrm{~J})$

\section{Conclusions}

The method used in this work allows us to study the behaviour of layered elements of PCM structures under the influence of non-stationary loads of various types in the presence of interlayer defects of various shapes, sizes and locations. In particular, take into account the destruction of the matrix and fibres and the degradation of the adhesive connection of layers (the growth of delamination). In this paper, we demonstrated the behaviour of a cylindrical circular reinforced shell in the case of impact in the presence of elliptical defects.

\section{References}

[1]. Medvedskiy, A. L., Rabinskiy, L. N., Martirosov, M. I., Ershova, A. Y., \& Khomchenko, A. V. (2019). Changes in strength of polymer composite panels with interlayer defects under the action of unsteady load. Asia Life Sciences, (1 Suppl. 21), 565-576.

[2]. Li, X., Ma, D., Liu, H., Tan, W., Gong, X., Zhang, C., \& Li, Y. (2019). Assessment of failure criteria and damage evolution methods for composite laminates under low-velocity impact. Composite structures, 207, 727-739.

[3]. Ebrahimi, F., Hashemabadi, D., Habibi, M., \& Safarpour, H. (2020). Thermal buckling and forced vibration characteristics of a porous GNP reinforced nanocomposite cylindrical shell. Microsystem Technologies, 26(2), 461-473.
[4]. De Luca, A., \& Caputo, F. (2017). A review on analytical failure criteria for composite materials. AIMS Materials Science, 4(5), 1165-1185.

[5]. Jiang, S., Sun, F., \& Fan, H. (2017). Multi-failure theory of composite orthogrid sandwich cylinder. Aerospace Science and Technology, 70, 520525.

[6]. Gu, J., \& Chen, P. (2017). Some modifications of Hashin's failure criteria for unidirectional composite materials. Composite Structures, 182, 143-152.

[7]. Chang F-K, Chang K-Y. (1987). Post-Failure Analysis of Bolted Composite Joints in Tension or Shear-Out Mode Failure. Journal of Composite Materials, 21(9):809-833. doi: $\underline{10.1177 / 002199838702100903}$

[8]. Kwon, Y. W., \& Bang, H. (2018). The finite element method using MATLAB. CRC press.

[9]. Rahimi, A., Alibeigloo, A., \& Safarpour, M. (2020). Three-dimensional static and free vibration analysis of graphene platelet-reinforced porous composite cylindrical shell. Journal of Vibration and Control, 26(19-20), 1627-1645.

[10]. Rao, S. S. (2017). The finite element method in engineering. Butterworth-heinemann.

[11]. Reddy, J. N. (2019). Introduction to the finite element method. McGraw-Hill Education.

[12]. Treutenaere, S., Lauro, F., Bennani, B., Haugou, G., Xu, W., Matsumoto, T., ... \& Ngueveu, Y. C. (2017). Numerical Evaluation of Low-Speed Impact Behaviour of a Fabric Layered Composite Plate in an Industrial context. 11 th European LS-DYNA Conference 2017, Salzburg, Austria. 

[13]. Jackson, K. E., Fasanella, E. L., \& Littell, J. D.
(2017, May). Development of a continuum damage mechanics Material Model of a Graphite-Kevlar ${ }^{\circledR}$ Hybrid Fabric for Simulating the Impact response of energy absorbing subfloor concepts. In Proceedings from the 73rd Annual American Helicopter Society Annual Forum and Technology Display. Fort Worth, TX.
[14]. Muflahi, S. A., Mohamed, G. F., \& Hallett, S. R. (2014, June). Investigation of delamination modeling capabilities for thin composite structures in LSDYNA. In 13th international LS-DYNA users conference.

[15]. Pronina, P. F., Tushavina, O. V., \& Starovoitov, E. I. (2020). Study of the radiation situation in moscow by investigating elastoplastic bodies in a neutron flux taking into account thermal effects. Periodico Tche Quimica, 17(35), 753-764. 